\title{
PENERAPAN IoT (Internet of Thing) TERHADAP SISTEM PENDETEKSI KESUBURAN TANAH PADA LAHAN PERKEBUNAN
}

\author{
Lazro eko Putra Daniel Sinambela, Ali Mahmudin, Karina Auliasari \\ Program Studi Teknik Informatika S1, Fakultas Teknologi Industri \\ Institut Teknologi Nasional Malang, Jalan Raya Karanglo km 2 Malang, Indonesia \\ Email anda
}

\begin{abstract}
ABSTRAK
Pada sektor pertanian tanah merupakan faktor yang berperan sangat penting dalam menentukan usaha pertanian. Dalam penelitian terkait untuk mengetahui kelayakan suatu daerah pertanian atau jenis tanaman pertanian dapat dilakukan dengan mengadakan sebuah penilaian kelayakan atau cocok tidaknya suatu daerah dengan tanaman yang bisa tumbuh atau hidup di daerah tersebut. Metode yang digunakan dalam perancangan perangkat lunak ini adalah metode waterfall.

Untuk itulah akan dikembangkan alat pendeteksi kesuburan tanah yang dapat menampilkan keadaan secara visual pada fitur monitoring dan dapat dikendalikan secara efisien dengan media wireless lewat website. Disamping itu dengan ditambahkannya sensor $\mathrm{pH}$ untuk mendeteksi suatu kadar $\mathrm{pH}$ tanah agar dapat membantu para petani atau sesorang menentukan tumbuhan apa yang sangat cocok untuk tanah tersebut.

Pengembangan sytem monitoring kedalam system operasi windows berplatform website dengan bantuan modul ESP8266 untuk mempermudahkan penggunaan dalam memantau dan memperoleh data kadar kelembapan dan kadar $\mathrm{pH}$ secara efisien, Sistem monitoring online pendeteksi kelembapan tanah yang sederhana dan efisien ini menggunakan mikrokontroler Arduino Uno sebagai pengendali utama, Sensor kelembapan sebagai pendeteksi tingkat kelembapan suatu tanah, Sensor pH sebagai pengukur kandungan kadar $\mathrm{pH}$ dalam suatu tanah. Mikrokontroler akan memerintahkan Sensor kelembapan dan sensor $\mathrm{pH}$ untuk mendeteksi kandungan kadar dalam tanah, Apa bila data dari kedua sensor sudah di dapatkan maka data tersebuat akan masuk kedalam Website dengan meleaui module ESP8266 sebagai koneksi arduino dengam Website, kemudian dari daa tersebut akan menampilakan berupa grafik serta akan menampilkan rekomendasi jenis tanaman yang sesuai dengan kandungan tanah.
\end{abstract}

\section{Kata Kunci : Sensor pH, Alat Pendeteksi Kesuburan tanah,ESP8266,jenis tanaman,Internet Of Things}

\section{PENDAHULUAN}

Pada sektor pertanian tanah merupakan faktor yang berperan sangat penting dalam menentukan usaha pertanian. Setiap daerah memiliki tingkat kesuburan tanah yang berbeda-beda, tergantung dari jenis tanah dan letak geografis suatu daerah. Jadi, kesuburan tanah merupakan salah satu faktor penentu keberhasilan usaha pertanian. Namun ada kalanya banyak usaha pertanian yang gagal karena kurangnya pemahaman tentang tingkat kesuburan tanah untuk jenis tanaman tertentu. Dalam penelitian terkait untuk mengetahui kelayakan suatu daerah pertanian atau jenis tanaman pertanian dapat dilakukan dengan mengadakan sebuah penilaian kelayakan atau cocok tidaknya suatu daerah dengan tanaman yang bisa tumbuh atau hidup di daerah tersebut. Metode yang digunakan dalam perancangan perangkat lunak ini adalah metode waterfall. Perangkat lunak ini dibuat dengan menggunakan bahasa pemrograman php, sedangkan basis data menggunakan MySQL. Sistem ini menerima input berupa data tanaman dan data daerah. Sedangkan output dari sistem ini berupa rekomendasi jenis tanaman dan daerah pertanian yang sesuai untuk hidup didaerah tertentu. Dengan adanya perangkat lunak ini akan lebih mempermudah pengguna dalam memantau maupun mendapatkan informasi tentang pertanian baik daerah maupun jenis tanaman pertanian. Namun pada pengembangan robot ini menggunakan system mekanik yang kemudian dikontrol dengan menggunakan Arduino. Robot ini adalah sebuah sistem prototipe kelembapan tanah dengan inputan menggunakan sensor Soil hygrometer detection yang berfungsi untuk mendeteksi suatu kadar air dalam tanah yang nantinya hasil dari sensor tersebut oleh Arduino dan akan di outputkan ke website dengan bantuan wireless.

Untuk itulah akan dikembangkan alat pendeteksi kesuburan tanah yang dapat menampilkan keadaan secara visual pada fitur monitoring dan dapat dikendalikan secara efisien dengan media wireless lewat website. Disamping itu dengan ditambahkannya sensor $\mathrm{pH}$ untuk mendeteksi suatu kadar $\mathrm{pH}$ tanah agar dapat membantu para petani atau sesorang menentukan tumbuhan apa yang sangat cocok untuk tanah tersebut.

\section{TINJAUAN PUSTAKA}

2.1 Penelitian Terdahulu

Pada penelitian dengan Sistem Kesuburan Tanah Pada Desa Cihaur Kelompok Tani Bina Mandari. Dari penelitian ini adalah membuat suatu 
system yang dapat mengetahui subur atau tidaknya tanah yaitu dengan menentukan kelembapan air yang ada di dalam tanah tersebut, dan robot pendeteksi kesuburan tanah juga dapat membedakan 3 jenis tanah di antaranya adalah tanah yang tidak subur, tanah yang kesuburannya sedang, dan tanah dengan kesuburan yang bagus dengan mengacu pada program yang telah dibuat $($ tidak subur $=$ nilai sensor $>700$, kesuburan sedang $=$ nilai sensor $>450$ dan $<700$, Kesuburan bagus $=$ nilai $>100$ dan $<450)$ [1].

Iwan juga menjelaskan Pada penelitian dengan Sistem Pendeteksi Tingkat Kesuburan Tanah untuk Menentukan Tingkat Perbandingan Penggunaan Pupuk Organik dan Anorganik pada Lahan Pertanian Menggunakan Arduino. Tujuan dari penelitian ini adalah untuk merancang dan membuat sistem pendeteksi kesuburan tanah untuk menentukan perbandingan penggunaan pupuk organik dan anorganik pada lahan pertanian menggunakan Arduino, sehingga para petani dapat mengetahui tingkat kesuburan lahan pertaniannya tersebut agar dapat menentukan jumlah pemberian pupuk organik dan anorganik. Hal ini dibuktikan berdasarkan hasil pengujian white box dan Black box. Kemudian diperkuat oleh hasil penyebaran kuisioner ke user target yang dalam hal ini adalah para petani [2].

Hannif izzatul islam juga menjelaskan dalam jurnal nya bahwa kebutuhan akan system yang dapat melakukan monitoring dan pengontrolan jarak jauh semakin meningkat tiap tahun nya, sejalan dengan kehidupan manusia, sehingga dapat mempermudah hidup manusia. Sehingga terciptalah sebuah system control dan monitoring jarak jauh yang memanfaatkan mikrokontroler dikarenakan biayanya murah dan luas

Untuk menciptakan system tersebut diperlukan sebuah aplikasi dan kontroler yang dapat berkolaborasi, dimana aplikasi tersebut dapat mengakses perangkat system melalui jaringan computer. Aplikasi ini berfungsi sebagai interface, pengolah data, dan control jarak jauh [3].

Pemeliharaan tanaman terkadang memerlukan penanganan yang khusus salah satunya pada green house. Kelemahan pada green house yang sudah ada adalah kondisi tanaman yang tidak dapat dimonitor dan dikontrol dari jarak jauh. Pada peneltitian Adriantantri, E. dan Irawan, J.D tentang Implementasi IoT Pada Remote Monitoring Dan Controlling Green House menerapkan perkembangan teknologi yaitu IoT (Internet of Things) yang digunakan pada monitoring dan controlling green house jarak jauh. Prinsip kerja pada green house yaitu dengan memanfaatkan jaringan internet yang menghubungkan sensor - sensor pada rangkaian controller, maka suhu, kelembaban dan intensitas cahaya pada green house dapat dimonitoring dan diatur dari jarak jauh. Pada aplikasi yang telah dibuat bahwa nilai suhu, kelembaban dan intensitas cahaya dapat dilihat dan petani dapat mengatur suhu, kelembaban dan intensitas cahaya yang dibutuhkan kondisi green house tersebut. Proses dari melakukan pengaturan akan dikirim dan diterima oleh mikrokontroler di green house, setelah diterima selanjutnya akan dijaga kondisi green house sesuai pengaturan yang telah diberikan [4].

\subsection{Arduino Uno}

Arduino Uno (Gambar 2.1) adalah board mikrokontroler yang di dalamnya terdapat mikrokontroler, penggunaan jenis mikrokontroler-nya berbeda - beda tergantung spesifikasinya. Pada Arduino Uno diguanakan mikrokontroler berbasis ATmega328. Memiliki 14 pin input dari output digital dimana 6 pin input tersebut dapat digunakan sebagai output PWM dan 6 pin input analog, $16 \mathrm{MHz}$ osilator kristal, koneksi USB, jack power, ICSP header, dan tombol reset.

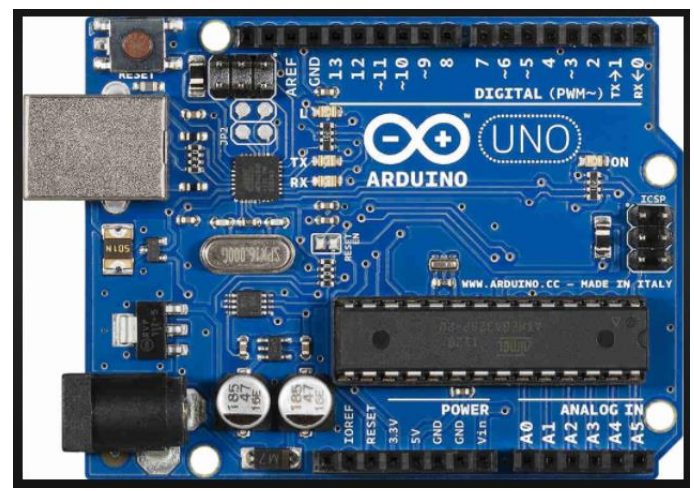

Gambar 2.1 Arduino Uno

\subsection{Sensor Kelembapan ( Soil Moisture )}

Soil moisture sensor (Gambar 2.2) adalah sensor kelembaban yang dapat mendeteksi kelembaban dalam tanah. Sensor ini sangat sederhana, tetapi ideal untuk memantau taman kota, atau tingkat air pada tanaman pekarangan. Sensor ini terdiri dua probe untuk melewatkan arus melalui tanah, kemudian membaca resistansinya untuk mendapatkan nilai tingkat kelembaban. Semakin banyak air membuat tanah lebih mudah menghantarkan listrik (resistansi kecil), sedangkan tanah yang kering sangat sulit menghantarkan listrik (resistansi besar). Sensor ini sangat membantu untuk mengingatkan tingkat kelembaban pada tanaman atau memantau kelembaban tanah. Soil moisture sensor FC-28 memiliki spesifikasi tegangan input sebesar $3.3 \mathrm{~V}$ atau $5 \mathrm{~V}$, tegangan output sebesar $0-4.2 \mathrm{~V}$, arus sebesar 35 $\mathrm{mA}$, dan memiliki value range ADC sebesar 1024 bit mulai dari $0-1023$ bit. 


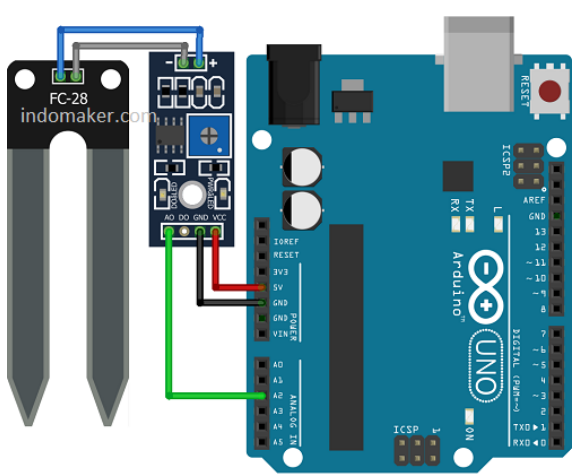

Gambar 2.2 Soil Moisture

\subsection{Module ESP8266}

ESP8266 (Gambar 2.3) adalah chip terintegrasi yang di rancang untuk kebutuhan terhubungnya dunia. Ia menawarkan solusi jaringan wifi yang lengkap dan mandiri, yang memungkinkan untuk menjadi host atau mentranfer semua fungsi jaringan wifi dan prosesor aplikasi lain dengan ATcommand sebagai perintah dasarnya. ESP8266 memiliki kemampuan pengolahan dan penyimpanan on-board 1 . yang kuat, yang memungkinkan untuk diintegrasikan dengan sensor dan aplikasi perangkat khusus lain melalui GPIOs dengan pengembangan yang mudah loading waktu yang minimal.

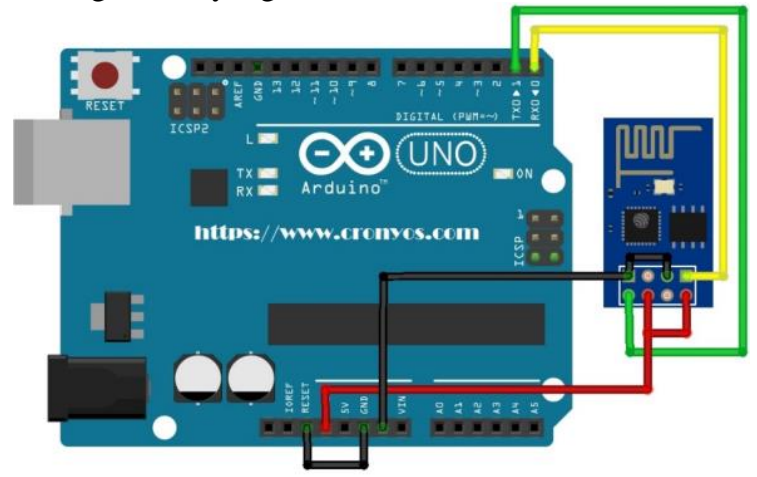

Gambar 2.3 Esp8266

fritzing

\subsection{Sensor pH}

Sensor Ph (Gambar 2.4) adalah sebuah alat elektronik yang berfungsi untuk mengukur ph ( derajat keasaman atau kebasaan ) suatu cairan ( ada elktroda khusus yang berfungsi untuk mengukur ph bahan - bahan semi - padat).

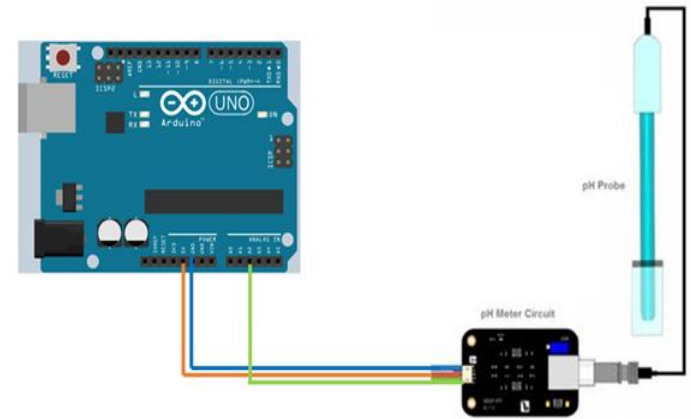

Gambar 2.4 Sensor pH

\subsection{IoT (Internet Of Think)}

Internet of Things (IOT) adalah sistem perangkat komputasi yang saling terkait, Mesin Mekanik dan Digital, Objek, Hewan atau Manusia yang dilengkapi dengan pengidentifikasi unik dan kemampuan untuk mentransfer Data melalui jaringan tanpa memerlukan manusia ke manusia atau manusia hanya dengan interaksi ke Komputer saja. Penggunaan IoT dapat di implementasikan pada berbagai hal salah satunya dalah perkuliahan, pelangan, dan sebagainya yang dapat di akses dari basis data.

\section{METODE PENELITIAN}

\subsection{Kebutuhan Fungsional}

Kebutuhan fungsional merupakan kebutuhan atau fungsi yang harus dimiliki atau mampu dilakukan oleh sebuah sistem. Dengan dideskripsikannya kebutuhan fungsional ini, maka suatu sistem memiliki sebuah target yang harus dipenuhi. Berikut beberapa kebutuhan fungsional sistem yang akan dibangun.

Perangkat Keras ( Hardware ) :

1. Arduino Uno R3

2. Modul Wifi ESP8266

3. Sensor Soil Moisture Pendeteksi Tingkat Kesuburan tanah

4. Sensor $\mathrm{pH}$ Pendeteksi kadar kandungan $\mathrm{pH}$ tanah

2. Perangkat Lunak ( Software):

1. Arduino IDE 6.11

2. Visual Studio Code

3. XAMPP

4. Web Browser

\subsection{Blok Diagram Sistem}

Diagram blok pada monitoring pada website dapat dilihat pada gambar dibawah ini :

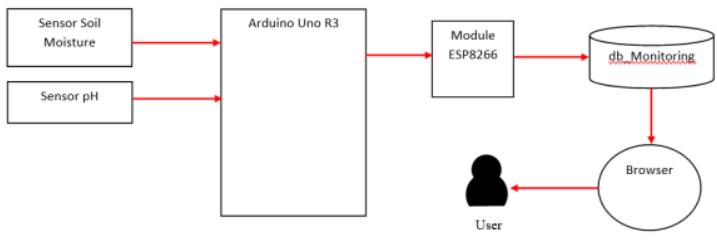

Gambar 3.1 Blok diagram system

Pada gambar diatas menjelaskan bahwa pada sistem monitoring pada alat menggunakan mikrokontroler arduino uno $\mathrm{r} 3$ sebagai pusat kontrol dan pengelola data. Data kadar kandungan $\mathrm{pH}$ dari sensor $\mathrm{pH}$, data kadar kelembapan tanah dari sensor Soil Moisture dikirim lalu diolah oleh arduino uno. Lalu diteruskan lewat modul ESP8266 data disimpan ke database dan dapat ditampilkan lewat website sehingga dapat dilihat oleh user. 


\subsection{Flowchart Sistem}

Adapun alur proses system dijelaskan pada gambar.

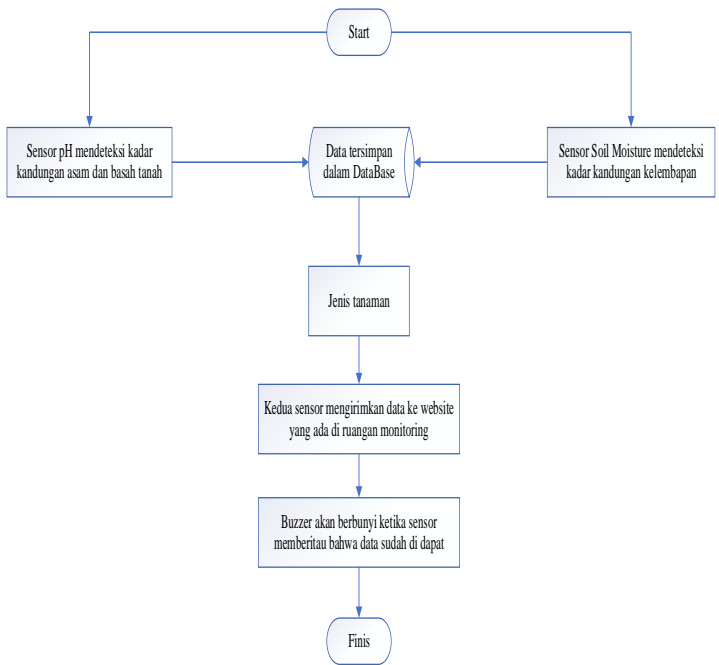

Gambar 3.2 Flowchart Sistem

Berdasarkan flowchart pada Gambar 3, Pertama Sensor $\mathrm{pH}$ akan mendeteksi tingkat ke asaman dan basah pada suatu tanah di lain sisi sensor Soil Moisture juga mendeteksi tingkat kelembapan suatu tanah yang di deteksi. Setelah dari semua data yang di dapat oleh kedua sensor akan tersimpan ke database dan sistem akan langsung menetukan jenis tanaman yang sesuia dengan kandungan $\mathrm{pH}$ dan kelembapan yang sudah di dapat setelah itu semua data - data akan di tampilkan ke website dengan bantuan ESP8266 agar data yang di dapat bisa langsung di tampilkan ke monitor dengan data yang sudah di dapat.Selanjutnya sensor buzzer akan berbunyi untuk memberitaukan bahwa kedua sensor sudah berjalan dengan baik.

\section{3,4 Flowchart Alat}

Adapun alur proses alat dijelaskan pada gambar

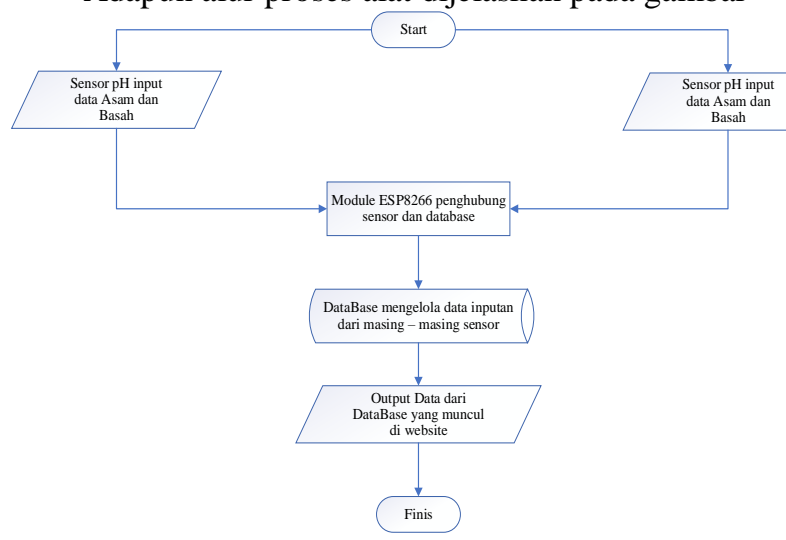

Pada gambar 3.4 ini penginputan variabel nilai kadar $\mathrm{pH}$ dan variabel kadar keasaman, kemudian di bantu oleh Module ESP8266 sebagai proses pengiriman data kedalam database agar tersimpan datanya sebagai arsip, setelah masuk kedalam database, datanya akan dikeluarkan ke tampilan website yang ada diruang monitoring sehingga datanya muncul secara realtime dan petani dapat mengetahui dengan cepat.

\subsection{Skema Rangkaina Alat}

Skema rangkaian alat merupakan gambaran dari model alat yang akan dibuat. Skema rangkaian keseluruhan hardware monitoring suhu kandang ayam, skema hardware dapat dilihat pada gambar 3.5.

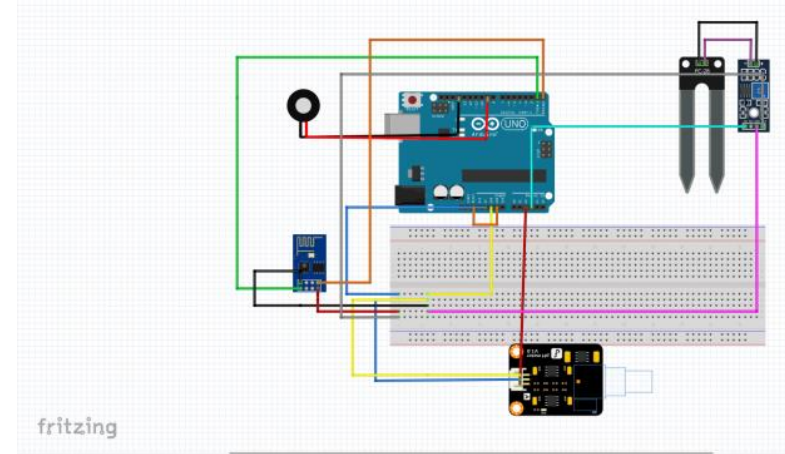

Gambar 3.4 Skema Rangkaian Alat

Alokasi konfigurasi dan penggunaan pin pada rangkaian alat ditunjukan pada Tabel 3.1 sebagai berikut:

\begin{tabular}{|c|c|}
\hline \multirow{2}{*}{ ARDUINO } & $\begin{array}{c}\text { Perangkat lain } \\
\text { Modul Wifi ESP8266 }\end{array}$ \\
\hline Ground & Ground \\
\hline $3.3 \mathrm{~V}$ & Vcc \\
\hline D1 & Rx \\
\hline D0 & Tx \\
\hline & Sensor Kelembapan \\
\hline $3.3 \mathrm{~V}$ & Ground \\
\hline Ground & Data \\
\hline A3 & Sensor pH \\
\hline & Vcc \\
\hline 5V & Ground \\
\hline Ground & Data \\
\hline A2 & Sensor Buzzer \\
\hline & Data \\
\hline Pin 9 & Ground \\
\hline Ground & \\
\hline &
\end{tabular}

Gambar 3.3 Flowchart Alat 


\section{HASIL DAN PEMBAHASAN}

4.1 Pengujian sensor Kelembapan

Pengujian komponen dari sensor kelembapan ini terdiri dari minimum Arduino Uno. Implementasi komponen yang terhubung pada minimum sistem arduino diletakkan pada sebuah tanah untuk mendeteksi tingkat kadar kelembapan. Adapun implemen tasi hardware di tunjukkan pada gambar 4.1

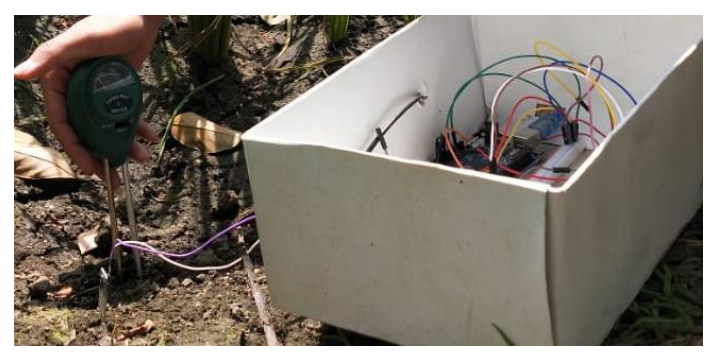

Gambar 4.1 Sensor Kelembapan

Pengujian ini menggunakan sensor soil moisture, sensor soil moisture diujikan bertujuan untuk mengetahui tingkat kelembapan tanah yang terdapat pada tabel 4.1.

Tabel 4.1 Pengujian Nilai Sensor Kelembapan

\begin{tabular}{|c|c|c|c|c|c|c|}
\hline \multirow{2}{*}{ No } & \multirow{2}{*}{$\begin{array}{l}\text { Kondisi } \\
\text { Tanah }\end{array}$} & \multirow{2}{*}{$\begin{array}{c}\text { Waktu } \\
\text { pengukuran }\end{array}$} & \multicolumn{4}{|c|}{$\begin{array}{l}\text { Nilai sensor pada } \\
\text { kedalaman tanah }\end{array}$} \\
\hline & & & $\begin{array}{c}5 \\
\mathrm{~cm}\end{array}$ & $\begin{array}{l}10 \\
\mathrm{~cm}\end{array}$ & $\begin{array}{l}15 \\
\mathrm{~cm}\end{array}$ & $\begin{array}{l}20 \\
\mathrm{~cm}\end{array}$ \\
\hline 1 & \multirow{5}{*}{$\begin{array}{l}\text { Lahan } \\
\text { perkebunan } \\
\text { penduduk }\end{array}$} & $\begin{array}{c}\text { Jam } \\
(06.00- \\
07.00)\end{array}$ & 84,5 & 86,0 & 86,5 & 87,8 \\
\hline 2 & & $\begin{array}{c}\text { Jam } \\
(09.00- \\
10.00)\end{array}$ & 75,5 & 76,0 & 76,5 & 79,1 \\
\hline 3 & & $\begin{array}{c}\text { Jam } \\
(12.00- \\
13.00)\end{array}$ & 65,7 & 68,1 & 68,9 & 70,0 \\
\hline 4 & & $\begin{array}{c}\text { Sore } \\
(16.00- \\
17.00)\end{array}$ & 70,7 & 73,8 & 74,6 & 75,1 \\
\hline 5 & & $\begin{array}{c}\text { Jam } \\
(18.00- \\
19.00) \\
\end{array}$ & 80,1 & 83,9 & 85,0 & 85,7 \\
\hline
\end{tabular}

Pada tabel 4.1 merupakan tabel hasil pengujian sensor soil moisture. Dari perbandingan yang diperoleh dari beberapa sempel tanah dan hasilnya setiap tanah memiliki kelembapan yang berbeda beda seperti tabel di atas.

\subsection{Pengujian Sensor $\mathrm{pH}$}

Pengujian komponen dari alat Sensor $\mathrm{pH}$ ini terdiri dari minimum sistem Arduino Uno. Implementasi komponen yang terhubung pada minimum sistem arduino diletakkan pada sebuah sebuah tanah yang nantinya mudah untuk mendeteksi tingkat kadar $\mathrm{pH}$ tanah . Adapaun implementasi hardware ditunjukkan pada Gambar 4.2

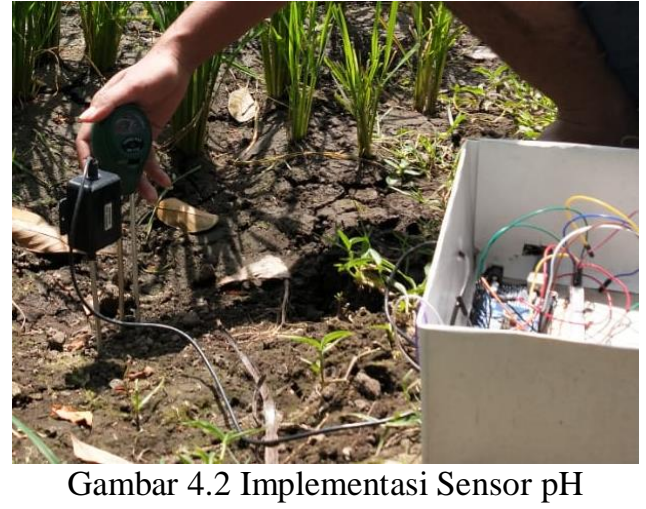

Pengujian ini menggunakan sensor $\mathrm{pH}$, sensor $\mathrm{pH}$ diujikan bertujuan untuk mengetahui tingkat kadar $\mathrm{pH}$ tanah yang terdapat pada tabel 4.2

Tabel 4.2 Pengujian Nilai Sensor $\mathrm{pH}$

\begin{tabular}{|c|c|c|c|c|}
\hline No & Kondisi Tanah & $\begin{array}{c}\text { Hasil } \\
\text { Kadar } \\
\mathrm{pH}\end{array}$ & Alat & $\begin{array}{c}\text { Presentase } \\
\text { Eror }\end{array}$ \\
\hline 1 & $\begin{array}{c}\text { Lahan } \\
\text { perkebunan 1 }\end{array}$ & 5.12 & 5.15 & 0.03 \\
\hline 2 & $\begin{array}{c}\text { Lahan } \\
\text { perkebunan 2 }\end{array}$ & 5,37 & 5.43 & 0.06 \\
\hline 3 & $\begin{array}{c}\text { Lahan } \\
\text { perkebunan 3 }\end{array}$ & 4,50 & 4.54 & 0.04 \\
\hline 4 & $\begin{array}{c}\text { Lahan } \\
\text { perkebunan 4 }\end{array}$ & 4,18 & 4.21 & 0.03 \\
\hline \multicolumn{5}{|c|}{ Presentase Error } \\
\hline
\end{tabular}

Pada Tabel 4.2 merupakan tabel hasil pengujian sensor pH. Dari perbandingan yang diperoleh dari beberapa sempel tanah dan hasilnya setiap tanah memiliki kadar $\mathrm{pH}$ yang berbeda beda seperti tabel di atas.

\subsection{Tampilan Tabel Monitoring}

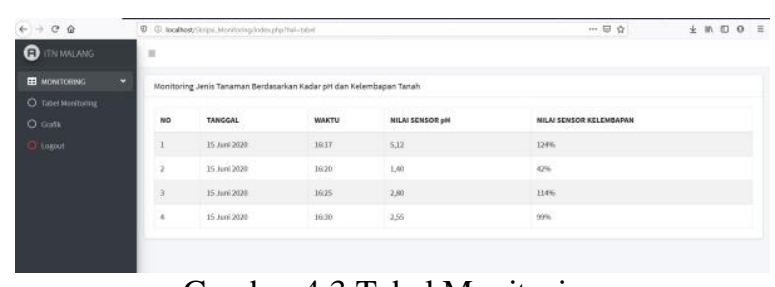

Gambar 4.3 Tabel Monitoring

Pada gambar 4.3 hasil pengujian yang sudah masuk dalam tabel pengujian di web monitoring bisa di lihat bawah tiap kandungan tanah sangat berbeda dari kadar pH dan kandungan kelembapannya. Hal ini nantinya yang akan bertujuan untuk merekomendasikan jenis tanam apa yang akan di tanam. 


\subsection{Tampilan Grafik}

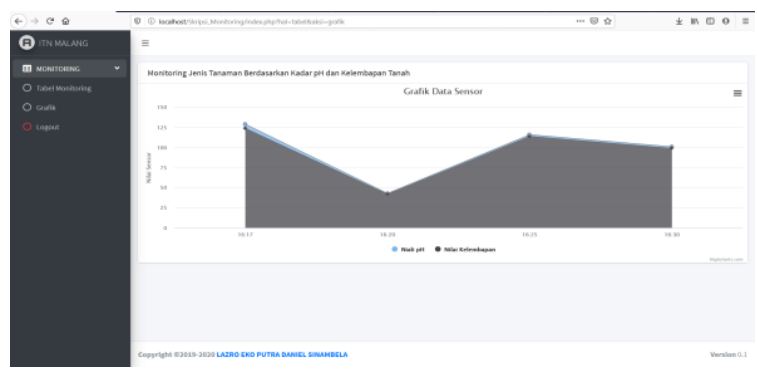

Gambar 4.4 Grafik

Pada Gambar 4.4 ini menapilkan grafik dari hasil data yang sudah di dapatkan dari kedua sensor tadi. Dari tampilan di atas menunjukan grafik 2 kondisi ya itu data dari nilai $\mathrm{pH}$ dan data dari nilai Kelembapan untuk tampilan data dari nilai $\mathrm{pH}$ dapat di lihat pada gambar 4.5 dan untuk tampilan nilai kadar kelembapan bisa di lihat pada gambar 4.6 di bawah.

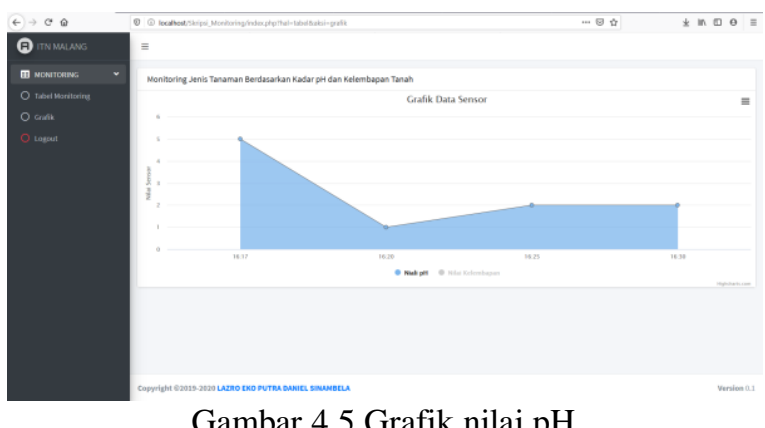

Pada tampilan gambar 4.5 ini kita bisa lihat bahwa grafik dari nilai $\mathrm{pH}$ tiap waktu sangat berbeda itu mendakan bahawa kondisi tanah kondis di tiap - tiap lokasi memiliki kandungan nilai $\mathrm{pH}$ yang berbeda beda.

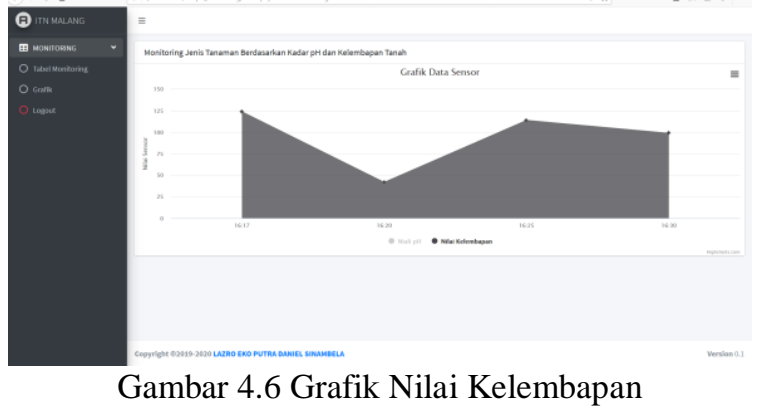

Pada tampilan gambar 4.6 ini kita bisa lihat bahwa grafik dari nilai kelembapan tiap waktu sangat berbeda itu mendakan bawha kondisi tanah di tiap - tiap tempat sangat berbeda seperti halnya nilai $\mathrm{pH}$ pada gambar 4.5 .

\subsection{Software Pada web broser}

Pengujian ini dilakukan untuk mengetahui respon terhadap beberapa web browser. Hasil uji dari web browser dapat dilihat pada Tabel 4.3
Tabel 4.3 Hasil Uji Web Browser

\begin{tabular}{|l|c|}
\hline \multicolumn{1}{|c|}{ Aspek Pengujian } & $\begin{array}{c}\text { Mozila } \\
\text { Firefox }\end{array}$ \\
\hline Menampilkan Hal. Kontrol dan Monitoring & $\sqrt{ }$ \\
\hline Fungsi Login & $\sqrt{ }$ \\
\hline Grafik & $\sqrt{ }$ \\
\hline Responsive & $\sqrt{ }$ \\
\hline Transmit data ke web & $\mathrm{X}$ \\
\hline
\end{tabular}

\section{KESIMPULAN DAN SARAN}

\subsection{Kesimpulan}

Berdasarkan beberapa hasil pengujian pada sistem monitoring dan kontrol yang telah dilakukan dapat disimpulkan :

1. Data dari Sensor Soil Moisture memiliki perbedaan pada tiap - tiap jenis tanah serta dari perbedaan tersebut bisa di nilai untuk merekomendasikan jenis tanaman yang akan di tanam.

2. Aplikasi berjalan dengan sangat baik, tanpa ada kesalahan saat melakukan pengujian dan dapat mengontrol alat sesuai kebutuhan.

3. Pengiriman dan penerimaan data menggunakan ESP8266 masi terkendala dengan jaringan.

4. Data dari Sensor pH memeiliki perbedaan pada tiap - tiap tanah yang sudah di deteksi oleh sensor dengan baik untuk mengukur kandungan kadar pH pada tanah oleh karna itu data dari nilai sensor ini akan membantu merekomendasikan jensis tanaman sesuai dengan kanduang $\mathrm{pH}$ tanah.

5. Untuk pengiriman data dari hardware ke webserver masi mengalami kendala pada jaringan pengiriman maka untuk sementara data yang masuk ke web masi berupa manual.

\subsection{Saran}

Adapun saran yang di peroleh untuk pengembangan selanjutnya antar lain :

1. Memberikan notifikasi berupa email apabila terdeteksi kerusakan pada sistem.

2. Menambahkan buzzer sebagai peringatan apabila terdapat object yang menghalangi sensor.

3. Untuk pengembangan kedepan, agar menambahkan beberapa allat sistem kontrol dan monitoring akses satu aplikasi

\section{DAFTAR PUSTAKA}

[1] Miko Andrianto, 2019, Penerapan IOT Pada Perawatan Tanaman Di Dalam Rumah.

[2] Usti Fatimah Sari Sitorus Pane, 2019, Implementasi Metode Fuzzy Untuk Sistem Identifikasi Kadar Elektrolit untuk Mengukur Tingkat Kesuburan Tanah Berbasis Mikrokontroler Arduino 
[3] Heru Agus Santoso. 2017, Analisis dan Perancangan Model Fuzzy Untuk Sistem Pakar Pendeteksi Tingkat Kesuburan

[4] Nini Firmawati. 2018, Rancang Bangun Prototipe Sistem Kontrol pH Tanah Untuk Tanaman Bawang Merah Menggunakan Sensor E201-C
[5] Iwan, 2016, Sistem Pendeteksi Tingkat Kesuburan Tanah untuk Menentukan Tingkat Perbandingan Penggunaan Pupuk Organik dan Anorganik pada Lahan Pertanian Menggunakan Arduino 